\title{
RELATIVE BIOAVAILABILITY OF TWO FORMULATIONS CONTAINING DAPAGLIFLOZIN 10 MG UNDER FED CONDITION IN A RANDOMIZED CROSSOVER STUDY IN HEALTHY CAUCASIAN SUBJECTS
}

\author{
MONICA OROIAN ${ }^{1,2}$, DIANA IOANA POP ${ }^{1,2}$, ANA-MARIA GHELDIU ${ }^{3 *}$, SANDEEP $^{2}$ \\ BHARDWAJ $^{2}$, ADRIANA MARCOVICI ${ }^{2}$, ARSHAD KHUROO $^{4}$, LAURIAN VLASE $^{1}$

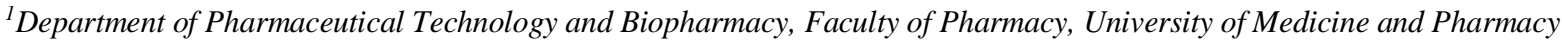 \\ "Iuliu Haţieganu”, Cluj-Napoca, Romania \\ ${ }^{2}$ Clinical Pharmacology and Pharmacokinetics Department, Terapia SA - a Sun Pharma Company, Cluj-Napoca, Romania \\ ${ }^{3}$ Department of Pharmaceutical Botany, Faculty of Pharmacy, University of Medicine and Pharmacy "Iuliu Haţieganu”, \\ Cluj-Napoca, Romania \\ ${ }^{4}$ Clinical Pharmacology and Pharmacokinetics Department, Gurugram, India
}

*corresponding author: anamaria.gheldiu@yahoo.com

Manuscript received: July 2019

\begin{abstract}
The study aimed to evaluate the bioequivalence of a $10 \mathrm{mg}$ dapagliflozin immediate release tablet, developed by Sun Pharmaceutical Industries, India, with the reference product Farxiga ${ }^{\circledR}$ (AstraZeneca Pharmaceuticals LP, USA). The bioequivalence was assessed on 44 healthy Caucasian subjects under fed condition, of which 33 completed both study periods. The clinical trial was designed as an open label, randomized, single-dose, two-treatment, two-period, two-sequence, crossover study, with a wash-out period of 7 days. During both study periods, blood samples were collected before drug administration and post-dose until 48 hours. Dapagliflozin plasma concentrations were determined by a validated LC-MS/MS method. The non-compartmental method was employed for the pharmacokinetic (PK) analysis of data and ANOVA test was used to evaluate the logarithmically transformed values of $\mathrm{C}_{\max }$ and AUCs. The $90 \%$ confidence intervals for the evaluated PK parameters were within the accepted range for bioequivalence $(80.00-125.00 \%)$, therefore the test product is bioequivalent with the reference product, under fed condition.
\end{abstract}

\section{Rezumat}

Studiul a vizat evaluarea bioechivalenței unui comprimat cu eliberare imediată de $10 \mathrm{mg}$ dapagliflozină, dezvoltat de Sun Pharmaceutical Industries, India, cu produsul de referință Farxiga ${ }^{\circledR}$ (AstraZeneca Pharmaceuticals LP, SUA). Bioechivalența a fost evaluată pe 44 de subiecți sănătoși caucazieni în condiții post-prandiale, dintre care 33 au finalizat ambele perioade de studiu. Design-ul studiului clinic a fost unul deschis, randomizat, cu doză unică, două tratamente, două perioade, două secvențe, încrucișat, cu o perioadă de wash-out de 7 zile. În timpul ambelor perioade de studiu, probele de sânge au fost colectate înainte de administrarea medicamentului și post-doză până la 48 de ore. Concentrațiile plasmatice ale dapagliflozinei au fost determinate printr-o metodă validată LC-MS/MS. Metoda non-compartimentală a fost utilizată pentru analiza farmacocinetică a datelor, iar testul ANOVA a fost utilizat pentru a evalua valorile logaritmate ale $\mathrm{C}_{\max }$ și ASC. Intervalele de încredere de $90 \%$ pentru parametri farmacocinetici evaluați au fost în intervalul acceptat pentru bioechivalență $(80,00-125,00 \%)$, prin urmare, produsul test este bioechivalent cu produsul de referință, în condiții post-prandiale.

Keywords: pharmacokinetics, bioequivalence, dapagliflozin, diabetes mellitus type 2

\section{Introduction}

Nowadays, diabetes is one of the most important and challenging metabolic illness $[6,18]$. It is currently classified in type 1 diabetes (which is an autoimmune $\beta$-cell destruction that leads to insulin deficiency and usually appears in infancy), type 2 diabetes (which appears because of an insulin resistance after a progressive loss of insulin secretion), gestational diabetes mellitus, and diabetes due to other causes such as pancreatitis or drug/chemical-induced diabetes [15].
The number of patients diagnosed with Type 2 diabetes mellitus (T2DM) is increasing every year [2, 8, 9]. According to National Institute of Diabetes, Digestive and Kidney Disease from USA (NIDDK) an estimated of 30.3 million people are diagnosed with diabetes [22]. Furthermore, the NIDDK also states that about one out of four patients with diabetes are not aware that they suffer from this disease while an estimated of 84.1 million Americans aged 18 years or older suffer from pre-diabetes symptoms [22]

The clinical approaches of T2DM, according to the therapeutic guidelines of several international 
organizations, include both non-pharmacological treatment (with diet and exercise) and pharmacological treatment [21].

While for type 1 diabetes insulin is the most common treatment applied to patients, for type 2 diabetes the oral hypoglycaemic agents are used to obtained control over the illness $[1,2,6,9]$. In the past years, inhibitors of the human sodium-glucose co-transporter 2 (SGLT2) such as dapagliflozin, which is first in this class, were shown to improve glycaemic control in patients with T2DM [1, 18, 19, 21].

SGLT2 is predominantly expressed in the proximal tubule of the kidneys where is responsible for the renal glucose reabsorption [2]. Dapagliflozin selectively inhibits the SGLT2, thus it blocks the glucose reabsorption and increases glycosuria (the excretion of glucose in urine). Therefore, dapagliflozin improves the glycaemic control in adults when combined with diet and exercise. By excreting the glucose in the urine, dapagliflozin leads to weight loss [4]. Dapagliflozin improves glycaemic control and prevents administration of increased doses of insulin in patients who cannot take metformin due to intolerance. At the same time, it was demonstrated to improve patients' weight and lead to minor changes in lipid levels [3].

The molecule was first approved by the Food and Drug Administration to be used by patients diagnosed with T2DM in January 2014 [18]. Since then, in March 2019 the European Commission (EC) announced the approval of dapagliflozin to be used in patients diagnosed with type-1 diabetes mellitus (T1DM) in cases when treatment with insulin does not provide an adequate control of glycaemia [23]. It is currently used as an adjunct to insulin treatment in patients with $\mathrm{BMI} \geq 27 \mathrm{~kg} / \mathrm{m}^{2}$ and as treatment for obese patients diagnosed with T2DM [12, 23].

Studies had demonstrated that after oral administration of dapagliflozin a maximum plasma concentration $\left(\mathrm{C}_{\max }\right)$ is obtained within 1 hour under fasting conditions [19]. Under fed condition, the absorption is delayed and the time to maximum plasma concentration $\left(t_{\max }\right)$ increases to 2 hours while the $\mathrm{C}_{\max }$ decreases by $50 \%[13,19]$. Even though, a dose adjustment for dapagliflozin is not considered necessary and it can be administered regardless to food intake [11]. Due to high protein binding (91\%), the apparent volume of distribution is high (approximately $110 \mathrm{~L}$ ) and the mean half-life is 13 hours $[13,19]$. Oral bioavailability of dapagliflozin is around 78\% [19].

In terms of metabolism, dapagliflozin is primarily glucuronidated by uridine diphosphate glucuronyltransferase UGT1A9 to its inactive 3-O-glucuronide metabolite $(60.7 \%)$, while also being transformed to other minor glucuronidated metabolite $(5.4 \%)$, a deethylated metabolite $(<5 \%)$, and a hydroxylated metabolite $(<5 \%)[2,19]$. Around $75 \%$ of dapagliflozin is recovered in urine after oral administration with $1.6 \%$ of the dose remaining unchanged by metabolism. In addition, in the faeces $21 \%$ of the dose is excreted [19]. Prior to market approval of a new generic product, its bioequivalence is assessed with the reference product from the market where it is expected to be released $[16,17]$. Therefore, the purpose of the present clinical trial was to assess the relative bioavailability of a new generic formulation in comparison to a reference product already approved on the market, in healthy adult Caucasian subjects under fed conditions.

\section{Materials and Methods}

\section{Study design}

Prior to study initiation, the National Agency of Medicine and Medical Devices, Romania, and Bioethics National Committee of the Medicines and Medical Devices, Romania, approved the clinical study protocol.

The Bioethics National Committee of the Medicines and Medical Devices approved the Informed Consent Form and any other information provided to study subjects.

The study was conducted at the Clinical Pharmacology and Pharmacokinetics Department of Terapia SA Sun Pharma, Romania.

The clinical study protocol was registered in the EudraCT data base with the no. 2017-001027-42.

This clinical study was performed in accordance with the principles defined in the Guideline for Good Clinical Practice ICHE6(R2) (CPMP/ICH/135/95), the principles of the Declaration of Helsinki (Brazil 2013), and the Guideline on the Investigation of Bioequivalence by the European Medicines Agency, Committee for Medicinal Products for Human use. The clinical trial also committed to respect the draft guidance on generic drug development for dapagliflozin tablets and the Guidance for Industry - Bioavailability and Bioequivalence Studies for Orally Administered Drug Products - General considerations (2003) of the U.S. Food and Drug Administration.

The study was designed as an open label, crossover, balanced, randomized, two treatment, two periods and two sequences, single-dose, bioequivalence assay, comparing one test formulation to the reference formulation as immediate release tablets containing dapagliflozin $10 \mathrm{mg}$, under fed conditions. The washout period of 7 days was elected according to the FDA Guidance for Industry ( 5 times the elimination half-life of dapagliflozin, $\mathrm{t}_{1 / 2}=13 \mathrm{~h}$ ) in order to prevent the carry-over effect during the study periods $[16$, 17, 19].

In order to ensure the required fasting period the subjects were admitted to the Clinical Unit with at least 10.5 hours before administration of the study drugs.

Therefore, the subjects started the recommended high fat, high-calorie test meal, 30 minutes prior to administration of the investigational pharmaceutical 
product after a fasting period of at least 10 hours. The investigational medicinal products were administered with $240 \mathrm{~mL}$ of $20 \%$ glucose solution. In addition, approximately $60 \mathrm{~mL}$ of $20 \%$ glucose solution was administered approximately every 15 minutes for up to 4 hours after the dose in order to reduce hypoglycaemia. Food was not allowed for 4 hours after dosing. Drinking water was not allowed 1 hour before and after dosing. During housing in the Clinical Unit all subjects received the same standard meals, identical in both periods of the study.

Study subjects

Sample size estimation for the number of subjects was estimated from available in-house and literature study data on dapagliflozin. Test/Reference ratio was considered of $95-105 \%$ and intra-subject coefficient of variation $(\mathrm{CV})$ of approximately $24 \%$, therefore a number of 34 subjects were found to yield a power of $90 \%$ to show bioequivalence of the two products, under bioequivalence assumptions. However, in order to allow possible dropouts and/or withdrawals, it was decided to enrol 44 subjects in the study.

All subjects were informed prior admission about study details and each subject signed the written informed consent before applying any screening procedures. After evaluating the subjects' medical history, ECG, physical examination, routine blood analysis results and urine tests results, only healthy subjects were admitted in the clinical trial. Moreover, all subjects were tested for drugs use and alcohol consumption, while female subjects were tested for pregnancy. All admitted subjects were adult Caucasian subjects, aged between 18 - 45 years, with a non-vegetarian diet habit and a body mass index (BMI) in the range of $18.5 \mathrm{~kg} / \mathrm{m}^{2}$ to $29.0 \mathrm{~kg} / \mathrm{m}^{2}$.

Study drugs

The investigational pharmaceutical product tested (T) in the present study was a new immediate release formulation containing dapagliflozin $10 \mathrm{mg}$. The reference product $(\mathrm{R})$ used was Farxiga ${ }^{\circledR}$ immediate release tablets (containing dapagliflozin $10 \mathrm{mg}$ ) manufactured by AstraZeneca Pharmaceuticals LP, Mount Vernon Ireland, for AstraZeneca Pharmaceuticals LP, USA. For assigning the treatment to subjects, a randomization schedule was generated using SAS ${ }^{\circledR}$ system for Windows release 9.1.3, SAS Institute Inc., USA. The subjects received alternatively the test formulation or the reference formulation in each period of the study.

Sample collection and processing

Blood samples for PK analysis were collected in $\mathrm{K}_{3}$ EDTA vacutainers through indwelling cannula placed in the forearm veins or through a vein puncture as follows: pre-dose and at $0.25,0.50,0.75,1.00,1.25$, $1.50,1.75,2.00,2.33,2.67,3.00,3.50,4.00,5.00$, $6.00,8.00,10.00,12.00,18.00,24.00,30.00,36.00$ and 48.00 hours post-dose in each study period.

All blood samples were collected and processed under low light conditions and kept on ice-cold water bath. For the separation of plasma, the samples were centrifuged under refrigeration, for 15 minutes at a speed of $4000 \mathrm{rpm}$ and a set temperature of $4^{\circ} \mathrm{C}$. Plasma sample preparation was accomplished by solid phase extraction $[13,14]$.

Bioanalytical method

For the determination of dapagliflozin in plasma it was used a validated LC-MS/MS method using Dapagliflozin D5 as internal standard. Mass spectrometry was performed in the negative ion multiple reaction-monitoring mode with $\mathrm{M} / \mathrm{Z}$ transitions of $407.10 \rightarrow 329.20$ for dapagliflozin and $412.10 \rightarrow 334.10$ for internal standard (dapagliflozin D5) $[13,14]$.

Safety evaluation

Even though the safety of subjects was not defined as an objective of this study, they were monitored for adverse events throughout the study and they were specifically asked about any adverse events after admission, before dosing time, after dosing and during housing in the Clinical Unit in both periods and at the end of the study. A physician was available at the site of investigation for at least 48 hours post-dose during each period. In both study periods, the vital signs (axillary body temperature, sitting blood pressure and radial pulse) were measured and recorded at screening, prior to and after administration of the investigational products and at the end of the study. For the safety of subjects blood glucose levels were measured prior to dosing and at 2.5, 3.5 and 5.5 hours post dose in each study period.

Pharmacokinetic and Statistical analysis

The non-compartmental PK analysis was performed for dapagliflozin using Phoenix ${ }^{\circledR}$ WinNonlin 6.3 (Certara, USA) and the following $\mathrm{PK}$ parameters were calculated: $\mathrm{C}_{\max }, \mathrm{t}_{\max }, \mathrm{AUC}_{0-\mathrm{t}}, \mathrm{AUC}_{0-\infty}, \mathrm{AUC}_{\%}$ extrap and $\mathrm{t}_{1 / 2}$.

The statistical analysis was performed for log-transformed PK parameters $\left(\mathrm{C}_{\max }, \mathrm{AUC}_{0-\mathrm{t}}\right.$ and $\left.\mathrm{AUC}_{0-\infty}\right)$ using $\mathrm{SAS}$ software version 9.1.3.

The analysis used Type III sum of squares from ANOVA, each analysis of variance included least squared method (LSM) calculation, the difference between the adjusted formulation means and the standard error associated with the difference.

Ratios of means were calculated using the antilog of the differences of LSM for log-transformed $\mathrm{C}_{\max }$, $\mathrm{AUC}_{0-\mathrm{t}}$ and $\mathrm{AUC}_{0-\infty}$. The $90 \%$ confidence interval for the ratio of test $(\mathrm{T})$ and reference $(\mathrm{R})$ product averages for $\mathrm{PK}$ parameters $\mathrm{C}_{\max }$ and $\mathrm{AUC}_{0-\mathrm{t}}$ from analysis of log-transformed data should be between $80 \%$ and $125 \%$.

\section{Results and Discussion}

Forty-four healthy adult Caucasian subjects were enrolled in the clinical trial based on the inclusion and exclusion criteria mentioned in study protocol. The demographic profile of the subjects who completed the study is shown in Table I. The duration of each 
study period was of approximately 58.5 hours (from admission until the last sample collection).

Table I

Demographic profile of the subjects who completed the study

\begin{tabular}{lc}
\hline \multicolumn{1}{c}{ Characteristic } & Value \\
\hline Number of subjects & 33 \\
Gender (number) - Women & 9 \\
- Men & 24 \\
Age (years, mean \pm SD*) & $25.9 \pm 5.19$ \\
Weight $(\mathrm{kg}$, mean \pm SD*) & $69.97 \pm 13.718$ \\
Height (cm, mean \pm SD*) & $172.77 \pm 9.479$ \\
Smoker - Yes & 11 \\
- No & 22 \\
\hline \multicolumn{2}{c}{ *SD - standard deviation }
\end{tabular}

From the 44 included subjects, 33 completed the study. Safety evaluation was not a purpose of this clinical trial, however every subject was carefully monitored during study periods and each adverse event was noted. A number of 10 not serious adverse events were reported in this study (Table II). No study withdrawal was caused by these adverse events and the health status of subjects was not threatened during the clinical trial. Test and reference products were well tolerated by the study subjects. The reported adverse events were consistent with those declared in the scientific literature for dapagliflozin. Moreover, the results of clinical examination before and after the study (physical examination, sitting blood pressure, radial pulse measurement, and axillary body temperature), adverse events questioning, laboratory tests, 12 ECG, demonstrated that study medication did not induce any significant clinical alteration in healthy subjects.

Table II

Adverse events recorded during and at the study of the bioequivalence clinical trial

\begin{tabular}{llll}
\hline & During the study & At the end of the study \\
\hline- & 1 case of vaso-vagal reaction; & - & 1 case of increased triglycerides; \\
- & 1 case of diarrhoea syndrome; & - & 3 cases of leukocyturia; \\
- & 1 case of vomiting. & - & 2 cases of urinary infection; \\
& & - & 1 case of haematuria. \\
\hline
\end{tabular}

In Figure 1 are depicted the mean plasma concentration of dapagliflozin after single dose administration of
$10 \mathrm{mg}$ immediate release tablet test and reference product in 33 Caucasian subjects, under fed condition.

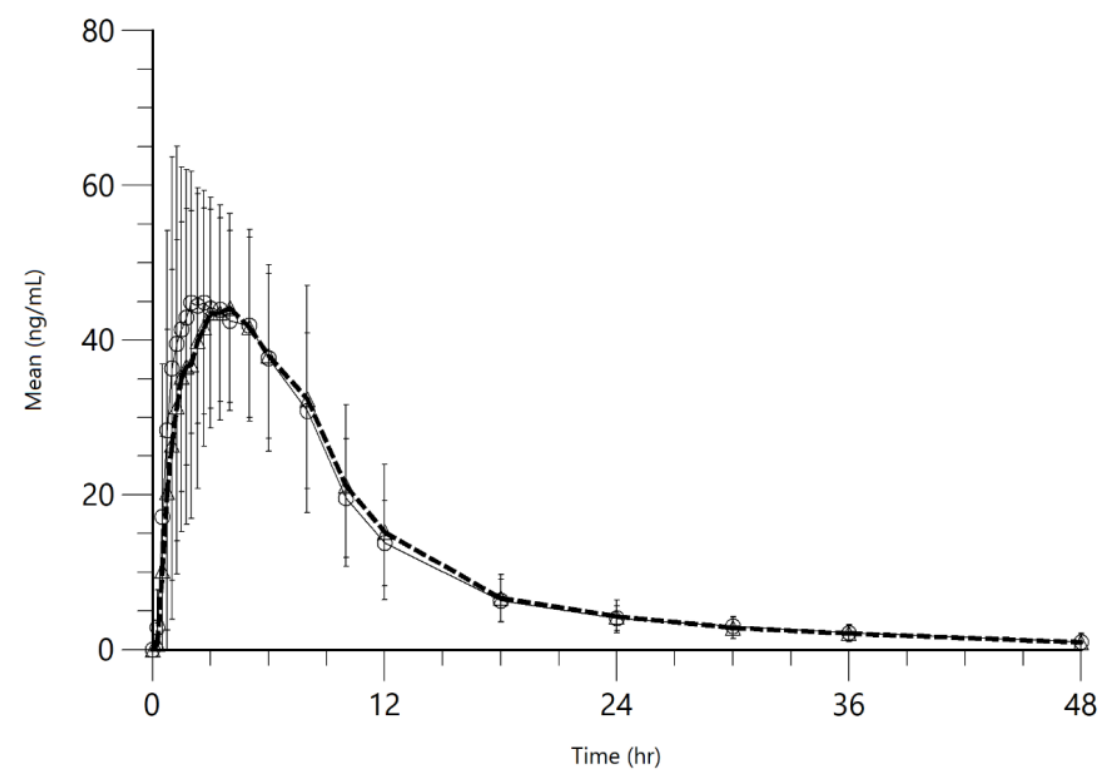

Figure 1.

Mean plasma concentration of dapagliflozin after administration of test product Dapagliflozin $10 \mathrm{mg}$ immediate release tablets (with full line) and the reference product immediate release tablets (with dotted line), in 33

Caucasian subjects under fed condition

In Table III are summarized the main PK parameters determined after administration of dapagliflozin $10 \mathrm{mg}$ immediate release tablet in test and reference product, under fed condition.

For the reference product administered under fed conditions, it was observed a mean $\mathrm{t}_{\max }$ of 3.62 hours and a $t_{1 / 2}$ of 12.26 hours. Under fed conditions, it was obtained a mean $\mathrm{C}_{\max }$ of $58.22 \mathrm{ng} / \mathrm{mL}$, as compared with $81.65 \mathrm{ng} / \mathrm{mL}$ obtained under fasting state [14]. This means a decrease of $\mathrm{C}_{\max }$ by $28.70 \%$. Under fed conditions it was obtained mean $\mathrm{AUC}_{0-\mathrm{t}}$ of $520.10 \mathrm{hr} * \mathrm{ng} / \mathrm{mL}$ and mean $\mathrm{AUC}_{0-\infty}$ of 
FARMACIA, 2020, Vol. 68, 1

$549.49 \mathrm{hr} * \mathrm{ng} / \mathrm{mL}$. Under fasting conditions it was obtained mean $\mathrm{AUC}_{0-\mathrm{t}}$ of $480.73 \mathrm{hr} * \mathrm{ng} / \mathrm{mL}$ and mean

$\mathrm{AUC}_{0-\infty}$ of $511.26 \mathrm{hr} * \mathrm{ng} / \mathrm{mL}[14]$.

Table III

Main pharmacokinetic parameters of dapagliflozin in 33 Caucasian healthy subjects following administration of dapagliflozin $10 \mathrm{mg}$ immediate release tablets under fed condition

\begin{tabular}{lcccccccc}
\hline Pharmacokinetic parameter & \multicolumn{2}{c}{ Mean } & \multicolumn{3}{c}{ SD $^{\mathbf{1}}$} & \multicolumn{2}{c}{$\mathbf{C V}^{\mathbf{2}}$} & \multicolumn{2}{c}{ Median } \\
\cline { 2 - 9 } & $\mathbf{R}$ & $\mathbf{T}$ & $\mathbf{R}$ & $\mathbf{T}$ & $\mathbf{R}$ & $\mathbf{T}$ & $\mathbf{R}$ & $\mathbf{T}$ \\
\hline $\mathbf{C}_{\mathbf{m a x}}(\mathbf{n g} / \mathbf{m L})$ & 58.22 & 60.83 & 13.41 & 17.61 & 23.04 & 28.96 & 57.66 & 56.09 \\
$\mathbf{A U C}_{\mathbf{0 - t}}(\mathbf{h r} * \mathbf{n g} / \mathbf{m L})$ & 521.08 & 522.94 & 159.55 & 132.61 & 30.62 & 25.36 & 488.85 & 520.87 \\
$\mathbf{A U C}_{\mathbf{0 - \infty}}(\mathbf{h r} * \mathbf{n g} / \mathbf{m L})$ & 524.72 & 527.37 & 157.74 & 131.95 & 30.06 & 25.02 & 495.81 & 521.48 \\
$\mathbf{t}_{\mathbf{1} / \mathbf{2}}(\mathbf{h r})$ & 12.64 & 13.06 & 6.17 & 6.24 & 48.78 & 49.14 & 11.89 & 10.50 \\
$\mathbf{t}_{\mathbf{m a x}}(\mathbf{h r})$ & 3.62 & 3.14 & 2.28 & 1.97 & 63.04 & 62.68 & 3.00 & 2.67 \\
$\mathbf{k}_{\mathbf{e l}}\left(\mathbf{h r}^{-\mathbf{1}}\right)$ & 0.07 & 0.06 & 0.03 & 0.03 & 48.28 & 39.50 & 0.06 & 0.07 \\
\hline
\end{tabular}

$\mathrm{SD}^{1}$ - standard deviation; $\mathrm{CV}^{2}$ - coefficient of variation; T represents Test Product (dapagliflozin 10 mg immediate release tablets); $\mathrm{R}$ represents Reference Product (Farxiga ${ }^{\circledR} 10 \mathrm{mg}$ immediate release tablets)

The ratios of LSM (with $90 \%$ confidence intervals) for $\mathrm{C}_{\max }$ was 103.66 , for $\mathrm{AUC}_{0-\mathrm{t}}$ was 101.35 , and for $\mathrm{AUC}_{0-\infty}$ was 101.48. The bioequivalence assessment is summarized in Table IV.
The mean values for the PK parameters were similar for the test and reference product. For the evaluated PK parameters no significant difference were found between both products under fed condition.

Table IV

Bioequivalence evaluation of pharmacokinetic parameters of dapagliflozin after administration of $10 \mathrm{mg}$ immediate release tablet (test and reference), in 33 healthy Caucasian subjects, under fed condition

\begin{tabular}{lccccc}
\hline \multicolumn{1}{c}{ Dependent } & Units & CI_90_Lower & CI_90_Upper & Ratio_\%Ref & Bioequivalence conclusion \\
\hline $\operatorname{Ln}\left(\mathrm{C}_{\max }\right)$ & $\mathrm{ng} / \mathrm{mL}$ & 95.93 & 112.01 & 103.66 & Bioequivalent \\
$\operatorname{Ln}\left(\mathrm{AUC}_{0-\mathrm{t}}\right)$ & $\mathrm{hr} * \mathrm{ng} / \mathrm{mL}$ & 98.84 & 103.93 & 101.35 & Bioequivalent \\
$\operatorname{Ln}\left(\mathrm{AUC}_{0-\infty}\right)$ & $\mathrm{hr} * \mathrm{ng} / \mathrm{mL}$ & 99.05 & 103.96 & 101.48 & Bioequivalent \\
\hline
\end{tabular}

*CI - confidence interval (90\%); Bioequivalent if 90\% CI: 80.00 - $125.00 \%$

The $90 \%$ confidence intervals for the ratio of test $(\mathrm{T})$ and reference $(\mathrm{R})$ product averages derived from the analysis of $\log$ transformed $\mathrm{PK}$ parameters $\mathrm{C}_{\max }$ and $\mathrm{AUC}_{0-\mathrm{t}}$ and were within $80.00-125.00 \%$ acceptance range for bioequivalence.

The maximum plasma concentration following dapagliflozin oral administration under fasting conditions is usually attained within 2 hours [14]. After administration under fed conditions, it was reported an increase in $\mathrm{t}_{\max }$ by approximately 1 hour, a decreases in $\mathrm{C}_{\max }$ by up to $50 \%$ while AUC was not altered [24].

In a study conducted on Brazilian healthy subjects, after administration of $10 \mathrm{mg}$ dapagliflozin under fed conditions were obtained comparable results for the geometric means ratios $(90 \% \mathrm{CI})$ for the parameters $\mathrm{C}_{\max }(91.9 \mathrm{ng} / \mathrm{mL}), \mathrm{AUC}_{0-\mathrm{t}}(100.1 \mathrm{hr} * \mathrm{ng} / \mathrm{mL})$ and $\mathrm{AUC}_{0-\infty}(99.1 \mathrm{hr} * \mathrm{ng} / \mathrm{mL})$ [5]. Another study conducted on healthy Hispanic/Latino subjects revealed that after a single dose of $10 \mathrm{mg}$ dapagliflozin the $\mathrm{C}_{\max }$ was $93.7 \mathrm{ng} / \mathrm{mL}$, while $t_{\max }$ was obtained after 2 hours from the administration [7].

All the results of the presented study are similar between test and reference product and are consistent with the information available from literature on dapagliflozin [11].

As the development of a new active molecule involves a lot of resources and time dedicated to research, the costs for the respective treatment may be quite high. Therefore, when a patent expires, different companies may develop a generic product that implies the conduct of a bioequivalence study to prove that the two products are equivalent and can be interchangeable [10].

Switching to a generic product may be cost effective for the patient, but also has to be as effective and safe as using the original product. Therefore, the bioequivalence studies aim to prove that the safety and therapeutically efficacy of the tested product is the same with the original drug product [20].

Due to the development of new generic products through the conduct of the bioequivalence studies, many patients with poor income may access the needed treatment. This can be helpful in diabetes patients for whom the costs of treatment can be high due to the complications that can appear, such as cardiovascular diseases, which involves the addition of other drugs to treat the associated conditions.

Based on these results, the test product and reference product are bioequivalent in healthy adult Caucasian subjects under fed condition. The products are therefore interchangeable in clinical practice.

\section{Conclusions}

Dapagliflozin $10 \mathrm{mg}$ immediate release tablets manufactured by Sun Pharmaceutical Industries, India, was proved bioequivalent with the reference product (Farxiga ${ }^{\circledR}$, AstraZeneca) in healthy adult Caucasian subjects under fed condition. By further registering the newly developed generic product, the economic 
burden for T2DM patients would decrease. Therefore, both type 1 and 2 diabetic patients will have access to an adequate treatment with lower financial costs.

\section{Conflict of interest}

The authors declare no conflict of interest.

The research study that was completed with the development of the licensed product was sponsored by Sun Pharmaceutical Industries, India, and conducted at Terapia SA - a Sun Pharma Company. Monica Oroian, as a currently employee of Terapia SA, declares that has no direct financial benefit if the submitted article is published.

\section{References}

1. Avogaro A, Giaccari A, Fioretto P, Genovese S, Purrello F, Giorgino F, Del Prato S, A consensus statement for the clinical use of the renal sodiumglucose co-transporter-2 inhibitor dapagliflozin in patients with type 2 diabetes mellitus. Expert Rev Clin Pharmacol., 2017; 10(7): 763-772.

2. Balakumar P, Sundram K, Dhanaraj SA, Dapagliflozin: glucuretic action and beyond. Pharmacol Res., 2014; 82: 34-39.

3. Bays HE, Sartipy P, Xu J, Sjöström CD, Underberg JA, Dapagliflozin in patients with type II diabetes mellitus, with and without elevated triglyceride and reduced high-density lipoprotein cholesterol levels. J Clin Lipidol., 2017; 11(2): 450-458.

4. Bertran E, Berlie HD, Nixon A, Jaber L, Does dapagliflozin affect energy intake and appetite? A randomized, controlled exploratory study in healthy subjects. Clin Pharm Drug Dev., 2019; 8(1): 119-125.

5. Boulton DW, Chang M, Griffen SC, Kitaura C, Lubin S, Pollack A, LaCreta F, Fed and fasted single-dose assessment of bioequivalence of dapagliflozin and metformin extended-release fixed-dose combination tablets relative to single-component dapagliflozin and metformin extended-release tablets in healthy subjects. Clin Ther., 2016; 38(1): 99-109.

6. Carpenter R, DiChiacchio T, Barker K, Interventions for self-management of type 2 diabetes: an integrative review. Int J Nurs Sci., 2019; 6(1): 70-91.

7. Chang M, Liu X, Cui D, Liang D, LaCreta F, Griffen SC, Lubin S, Quamina-Edghill D, Boulton DW, Bioequivalence, food effect, and steady-state assessment of dapagliflozin/metformin extended-release fixeddose combination tablets relative to single-component dapagliflozin and metformin extended-release tablets in healthy subjects. Clin Ther., 2015; 37(7): 1517-1528.

8. Fioretto P, Mansfield TA, Ptaszynska A, Yavin Y, Johnsson E, Parikh S, Long-term safety of dapagliflozin in older patients with type 2 diabetes mellitus: a pooled analysis of phase IIb/III studies. Drugs Aging, 2016; 33(7): 511-522.

9. Gomes MB, Rathmann W, Charbonnel B, Khunti K, Kosiborod M, Nicolucci A, Pocock SJ, Shestakova MV, Shimomura I, Tang F, Watada H, Chen H, CidRuzafa J, Fenici P, Hammar N, Surmont F, Ji L,
Treatment of type 2 diabetes mellitus worldwide: baseline patient characteristics in the global DISCOVER study. Diabetes Res Clin Pract., 2019; 151: 20-32.

10. Gothe H, Schall I, Saverno K, Mitrovic M. Luzak A, Brixner D, Siebert U, The impact of generic substitution on health and economic outcomes: a systematic review. Appl Health Econ Health Policy, 2015; 13(Suppl 1): S21-33.

11. Kasichayanula S, Liu X, Zhang W, Pfister M, Reele SB, Aubry AF, LaCreta FP, Boulton DW, Effect of a high-fat meal on the pharmacokinetics of dapagliflozin, a selective SGLT2 inhibitor, in healthy subjects. Diabetes Obes Metab., 2011; 13(8): 770-773.

12. Okamoto A, Yokokawa H, Sanada H, Naito T, Changes in levels of biomarkers associated with adipocyte function and insulin and glucagon kinetics during treatment with dapagliflozin among obese type 2 diabetes mellitus patients. Drugs R D., 2016; 16(3): 255-261.

13. Oroian M, Marcovici A, Pop, DI, Bhardwaj S, Khuroo A, Gheldiu AM, Vlase L, Kinetics of dapagliflozin after single dose oral administration of a $10 \mathrm{mg}$ immediate release tablet. Studia UBB Chemia, 2019; LXIV(2, Tom I): 297-308.

14. Oroian M, Pop DI, Gheldiu AM, Bhardwaj S, Marcovici A, Khuroo A, Vlase L, The relative bioavailability of two formulations containing $10 \mathrm{mg}$ Dapagliflozin assessed under fasting conditions in a randomized crossover study in healthy Caucasian subjects. Acta Med Marisiensis, 2020; 66(1); 1-5.

15. Petersmann A, Nauck M, Müller-Wieland D, Kerner W, Müller UA, Landgraf R, Freckmann G, Heinemann L, Definition, classification and diagnosis of diabetes mellitus. Exp Clin Endocrinol Diabetes, 2018; 126(07): 406-410.

16. Pop DI, Oroian M, Bhardwaj S, Marcovici A, Khuroo A, Kochhar R, Vlase L, Bioequivalence of two formulations of gliclazide in a randomized crossover study in healthy Caucasian subjects under fed condition. Farmacia, 2018; 66(4): 597-301.

17. Pop DI, Oroian M, Bhardwaj S, Marcovici A, Khuroo A, Kochhar R, Vlase L, Bioequivalence of two formulations of gliclazide in a randomized crossover study in healthy Caucasian subjects under fasting conditions. Clin Pharm Drug Dev., 2019; 8(1): 16-21.

18. Rizzo M, Al-Busaidi N, Rizvi AA, Dapagliflozin therapy in type-2 diabetes: current knowledge and future perspectives. Expert Opin Pharmacother., 2015; 16(3): 281-284.

19. Saeed MA, Narendran P, Dapagliflozin for the treatment of type 2 diabetes: a review of the literature. Drug Des Devel Ther., 2014; 8: 2493-2505.

20. Straka RJ, Keohane DJ, Liu LZ, Potential clinical and economic impact of switching branded medications to generics. Am J Ther., 2017; 24(3): e278-e289.

21. Vivian EM, Dapagliflozin: a new sodium-glucose cotransporter 2 inhibitor for treatment of type 2 diabetes. Am J Health Syst Pharm., 2015; 72(5): 361-372.

22. www.niddk.nih.gov.

23. www.ema.europa.eu.

24. www.accessdata.fda.gov. 